\title{
Contributo da intervençáo da terapia ocupacional nos Cuidados Paliativos
}

\author{
Hugo Miguel Candeias Baltazar ${ }^{a}$, Susana Cristina Costa Pestana ${ }^{b}$, \\ Maria Raquel Rodrigues Santana ${ }^{b}$ \\ aDelegação de Tavira, Cruz Vermelha Portuguesa, Tavira, Portugal.

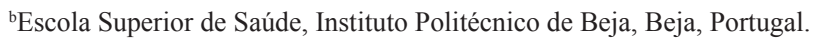

\begin{abstract}
Resumo: Introdução: Os Cuidados Paliativos (CP) definem-se como uma resposta ativa aos problemas decorrentes da doença prolongada, incurável e progressiva, através da identificação precoce, avaliação, tratamento da dor e outros problemas físicos, psicossociais e espirituais. Estes cuidados não estão suficientemente divulgados e sugere-se a realização e divulgação de mais estudos no âmbito da terapia ocupacional e de outras áreas da saúde. Objetivos: O principal objetivo desta investigação foi verificar o contributo da intervenção da terapia ocupacional nos CP e aprofundar conhecimentos acerca desta intervenção, através da descrição das principais metodologias utilizadas, para uma perceção integral da intervenção realizada nesta área. Método: Trata-se de um Estudo Descritivo simples, transversal e não experimental, desenvolvido em Portugal. Na coleta de dados foi aplicado um questionário autoadministrado pelos terapeutas ocupacionais. A amostra foi constituída por 15 terapeutas ocupacionais com prática clínica nos Cuidados Paliativos. Resultados: Verificou-se que as principais metodologias de intervenção são a Promoção da Relação Terapêutica, Acolhimento, Partilha de Informação, Aconselhamento, Educação, Orientação e Importância do Papel Ativo dos Familiares/Cuidadores em todo o processo, bem como a Importância da Relação Terapêutica, Acolhimento, Avaliação, Educação, Treino, Promoção do Envolvimento nas Atividades Significativas, Adaptação/Graduação e Utilização de Técnicas de Intervenção Específicas com o Cliente. Conclusão: Realça-se a congruência nas respostas obtidas em relação às principais metodologias de intervenção utilizadas pelos terapeutas ocupacionais nos CP. Este estudo busca um meio impulsionador para o contributo da intervenção da terapia ocupacional nesta área em Portugal.
\end{abstract}

Palavras-chave: Terapia Ocupacional, Hospitalização, Intervenção.

\section{Contribution of the occupational therapy intervention in Palliative Care}

\begin{abstract}
Introduction: Palliative Care (PC) is defined as an active response to problems arising from prolonged, incurable and progressive disease through early identification, assessment, treatment of pain and other physical, psychosocial and spiritual problems. This care is not sufficiently disclosed and it is suggested further studies and disclosure within the occupational therapy and other areas of health. Objectives: This investigation main objective was to determine the contribution of the occupational therapy intervention in PC and acquire deeper knowledge about this intervention by describing the main methodologies used for a full perception of the intervention carried out in this area. Methods: This is a simple, transversal and not experimental descriptive study, developed in Portugal. Data were collected using a questionnaire self-administered by the occupational therapists. The sample consisted of 15 occupational therapists with clinical practice in palliative care. Results: It was found that the main intervention methodologies are the Promotion of Therapeutic Relationship, Welcoming, Information Sharing, Counseling, Education, Orientation and Importance of Active Role of Family/Caregivers throughout the process, as well as the importance of Therapeutic relationship, Welcoming, Evaluation, Education, Training, Promotion Involvement in Significant Activities, Adaptation/Graduation and Use of Specific Intervention Techniques with the Client. Conclusion: The consistency in the responses obtained for major intervention methodologies used by occupational therapists in PC is emphasized. This study seeks a driving mean for the contribution of the Occupational Therapy intervention in Portugal.
\end{abstract}

Keywords: Occupational Therapy, Hospitalization, Intervention.

Autor para correspondência: Susana Cristina Costa Pestana, Escola Superior de Saúde, Instituto Politécnico de Beja, Rua Pedro Soares, Campus do Instituto Politécnico de Beja, Apartado 6155, CEP 7800-295, Beja, Portugal, e-mail: susana.pestana@ipbeja.pt

Recebido em Jul. 6, 2015; $1^{\text {a }}$ Revisão em Jul. 23, 2015; Aceito em Nov. 2, 2015. 


\section{Introdução}

Os Cuidados Paliativos (CP) surgiram oficialmente como prática distinta na área da atençáo em saúde na década de 1960, no Reino Unido (BOULAY, 2007). No entanto, as primeiras iniciativas em Portugal surgiram no início dos anos 90 do século passado (MARQUES et al., 2009).

A Associação Portuguesa de Cuidados Paliativos (ASSOCIAÇÃO..., 2014) define os CP como uma resposta ativa aos problemas decorrentes da doença prolongada, incurável e progressiva, através da prevenção e alívio do sofrimento e promoção da qualidade de vida aos clientes e familiares, mediante a identificação precoce, avaliação e tratamento da dor e outros problemas físicos, psicossociais e espirituais. Esta prestação de cuidados proporciona o alívio da dor e outros sintomas angustiantes, afirmando a vida e respeito à morte como um processo normal, permitindo ao cliente que viva tão ativamente quanto possível, e ainda auxilia a família a lidar pacientemente durante a doença e no próprio luto, defendendo que estes cuidados se aplicam no início do curso da doença, em conjunto com outras terapias, podendo influenciar positivamente o curso da doença (WORLD..., 2013). Carlo e Queiroz (2008) referem que os CP podem ser uma assistência direcionada a indivíduos com doenças crónico-degenerativas progressivas e não responsivas às terapias curativas com a presença de sintomatologia de controlo difícil e debilitante, caracterizando-se pela assistência integral e integrada, interdisciplinar e multiprofissional, que visa o alívio do sofrimento, proporcionando conforto e qualidade de vida.

Em 2010 foi aprovado o segundo Programa Nacional de Cuidados Paliativos (PNCP) em Portugal, baseado nas recomendaçôes da Organização Mundial de Saúde (OMS) para esta área, que refere que os CP são uma resposta integrante do Sistema Nacional de Saúde (SNS) flexível, focada nos cuidados domiciliários e considerando estes cuidados de saúde como essenciais (MARQUES et al., 2009).

Segundo Henning (2010), estes cuidados não estão suficientemente divulgados nem ao alcance de todos os clientes, e é imprescindível que a população tenha conhecimento da importância destes. Em Portugal verifica-se essa tendência, mas têm surgido algumas iniciativas e progressos no âmbito do seu desenvolvimento, apesar de ainda se encontrarem longe do que seria ambicionado (ASSOCIAÇÃO..., 2014). Com o surgimento da Rede Nacional de Cuidados Continuados Integrados (RNCCI), em 2006, o governo procurou replicar o sucesso destas equipas e de acordo com as estruturas e áreas de intervençáo. Segundo o Decreto-Lei no 101/2006, as respostas de CP em Portugal podem definir-se nas seguintes modalidades: Equipa Comunitária de Suporte em CP (ECSCP), Equipa intra-hospitalar de suporte em CP (EIHSCP) e Unidades de CP (UCP) (COSTA; OTHERO, 2014).

Segundo o Relatório de março de 2013 da RNCCI, existem 36 equipas de CP (25 são EIHSCP, das quais 7 também efetuam cuidados domiciliários e 11 são ECSCP que prestam açóes/CP. A APCP reconhece 22 equipas de $\mathrm{CP}$ das 36 equipas reconhecidas pelas RNCCI (ENTIDADE..., 2013). O número de profissionais de reabilitação nas equipas reconhecidas pela APCP é diminuto, e em geral as equipas são formadas por médicos e enfermeiros, seguidos por assistentes sociais e psicólogos (COSTA; OTHERO, 2014).

Os clientes que se encontram nos $\mathrm{CP}$ necessitam de um amplo cuidado para o alívio de sintomas de dor, fadiga, fraqueza e educação para a promoção $\mathrm{da}$ independência funcional e qualidade de vida. Estas necessidades são suprimidas mais facilmente através da intervenção de profissionais de reabilitação, fundamentais na prestação de cuidados interdisciplinares necessários ao longo de todas as fases da doença, em condiçốes rapidamente progressivas ou estáveis (COSTA; OTHERO, 2014). Ainda que sem regulamentaçáo que obrigue à existência de um terapeuta ocupacional nos serviços de CP em Portugal, é importante destacar a inserção do terapeuta ocupacional na maioria das tipologias da RNCCI, da qual fazem parte as UCP. Em Portugal existem 1024 terapeutas ocupacionais em CP (COSTA; OTHERO, 2014). Os CP são uma área de intervenção médica onde surgem ainda diversos dilemas éticos inerentes a esta intervenção e onde é necessário que os profissionais de saúde, nomeadamente os terapeutas ocupacionais, reflitam sobre estes dilemas (COSTA, 2012). Existem poucos estudos divulgados que evidenciam o contributo da intervenção do terapeuta ocupacional, bem como outras áreas de saúde, e sugere-se que sejam realizados mais estudos de terapia ocupacional e de outras áreas da saúde sobre os CP. Desta forma, é imprescindível que a população tenha conhecimento da importância dos CP, pois todos têm o direito ao alívio do sofrimento adequado e eficiente, e principalmente manter a dignidade até ao último momento de vida (HENNING, 2010).

Segundo Costa (2012), a terapia ocupacional é uma área da saúde focada nas atividades/ocupações significativas para o cliente, desde uma atividade da vida diária, como o vestir, até uma atividade de lazer, como o viajar. É necessário avaliar de que 
forma a dor e as preocupaçóes estáo a comprometer o desempenho ocupacional da pessoa e, assim, a sua qualidade de vida.

De acordo com Othero (2010), o terapeuta ocupacional tem um papel essencial no que respeita a ajudar a pessoa a manter a sua identidade ocupacional, bem como em redefinir os papéis ocupacionais, através da realização dos seus últimos desejos e da prestação de cuidados personalizados, com qualidade até ao último momento de vida. No âmbito dos $\mathrm{CP}$, o papel específico do terapeuta ocupacional é proporcionar ao cliente meios para manter as suas condições físicas e emocionais no desempenho de tarefas significativas, efetuar adaptações necessárias para a manutenção das funçóes físicas, cognitivas e sensoriais, bem como do conforto físico, controlo da dor, fadiga e outros sintomas, independentemente da fase da doença (COSTA; OTHERO, 2014).

Burkhardt et al. (2011) referem que o terapeuta ocupacional nos CP tem como função promover o envolvimento da pessoa em atividades funcionais para o tratamento de disfunçôes físicas e psicossociais, adaptaçáo à perda funcional, treino de atividades de vida diária de autocuidado, orientação e adaptação do estilo de vida, orientação para a gestão do tempo e conservaçáo de energia, bem como a utilização de equipamentos adaptativos e ajudas técnicas para prevenção de deformidades e controlo da dor.

A American Occupational Therapy Association (AMERICAN..., 2008), aponta as diferentes áreas em que o terapeuta ocupacional foca as suas intervençôes junto do cliente em CP: atividades de vida diária, atividades de vida diária instrumental, descanso e sono, lazer e participação social, relacionamento interpessoal. A atuação da terapia ocupacional é fundamental na procura pela manutenção de um sentido para a vida do cliente, muitas vezes num contexto de limitaçóes, como é o caso do cliente que se encontra nos CP. As açóes da terapia ocupacional envolvem a ocupaçáo, incluindo atividades de rotina, artes, trabalho, lazer, cultura, autocuidado e participaçáo social. Assim, procuram-se criar possibilidades para a continuidade dessas ocupaçôes, para que as atividades significativas sejam mantidas (OTHERO, 2010). A intervenção da terapia ocupacional em $\mathrm{CP}$ pode ser individual (no leito, na sala de terapia ocupacional, no domicílio, etc.) ou em grupo (grupos específicos, oficinas, atividades coletivas, atividades comemorativas, etc). Os atendimentos também são realizados com familiares e cuidadores, individualmente, em grupos de orientação e também em conferências familiares (COSTA; OTHERO, 2014).

Segundo Armitrage, citado por Oliveira (2008), as abordagens mais usadas pelo terapeuta ocupacional traduzem-se no treino e orientação nas AVD's, atividades físicas, massagem e exercícios para alívio e controlo da dor; orientação para a facilitação das tarefas no sentido da conservação de energia; estímulo de atividades físicas (de acordo com o grau de fadiga) para preservar a mobilidade e grau de independência; ensino aos cuidadores; confeção de adaptaçôes que facilitem o desempenho ocupacional; posicionamento adequado no leito e nas mudanças posturais para evitar contraturas, deformidades e escaras, bem como facilitar a mobilidade ativa e realizar atividades terapêuticas (expressivas, lúdicas, corporais e artesanais) que adiem o processo de perdas decorrentes da evoluçáo do quadro clínico.

A abordagem considera a situação atual do cliente (clínica e psicossocial), o seu prognóstico e as perspetivas futuras, respeitando as necessidades e desejos de todos os intervenientes no processo terapêutico, delineando objetivos realistas na procura da resolução de problemas e organização da rotina. Durante o processo terapêutico, as atividades propostas são direcionadas para a problemática identificada e referida pelo cliente, pelos cuidadores e pelos membros da equipa de saúde, para que dessa forma se consigam utilizar todos os recursos, técnicas e métodos disponíveis que vão da abordagem funcional à adaptação do ambiente (QUEIROZ, 2012). As metas estabelecidas devem ir ao encontro das competências remanescentes, das limitaçóes presentes, das necessidades e dos desejos do cliente e do cuidador, objetivando o conforto nas diferentes esferas do indivíduo e a qualidade de vida, através da realizaçáo de projetos a curto e médio prazo e que dão sentido e significado à vida de quem é acompanhado (QUEIROZ, 2012).

\section{Objetivos}

Dadas as dificuldades de divulgação e acesso à literatura acerca das práticas de intervenção dos terapeutas ocupacionais em CP, torna-se pertinente aprofundar conhecimentos acerca da intervençáo destes, através da descrição das principais metodologias utilizadas, para uma perceção integral da intervenção realizada nesta área de prática clínica. Este projeto de investigação tem como objeto de estudo a verificação do contributo da intervenção da terapia ocupacional nos CP. Através da recolha dos dados e de acordo com as metodologias de intervenção recolhidas, pretende-se que seja feito um levantamento acerca destas, bem como identificar os principais aspetos que podem contribuir para uma menor coerência e uniformização das práticas de intervençáo que são recomendadas para os profissionais de terapia ocupacional integrados nas Unidades de CP. 
No estudo poderão emergir novas abordagens e metodologias de intervenção nesta área de prática clínica, tendo em conta a importância que cada terapeuta ocupacional atribui a um determinado aspeto do cliente.

Visto que não existem estudos sobre esta temática, o projeto poderá ser uma mais-valia para que futuramente sejam definidas as linhas orientadoras para a utilização de metodologias de intervenção nesta área, por parte dos profissionais de terapia ocupacional.

\section{Método}

O presente projeto trata-se de um estudo descritivo simples, transversal e não experimental desenvolvido em Portugal, que pretende descrever um conceito relativo a uma população, num dado momento, sem a introdução de variáveis, no qual o investigador estuda uma situação, tal como ela se apresenta no meio natural, com vista a destacar as características de uma população, compreender fenómenos ainda mal-elucidados ou conceitos que foram pouco estudados, de maneira a obter uma visão geral de uma situação ou de uma populaçáo (FORTIN, 2006). Ambiciona descrever a intervenção da terapia ocupacional, através das metodologias de intervenção, bem como identificar os principais aspetos que podem contribuir para uma menor coerência e uniformização das práticas de intervenção que são recomendadas para os profissionais de terapia ocupacional integrados nas Unidades de CP.

A população em estudo foi constituída por terapeutas ocupacionais com experiência profissional em CP.

Trata-se de uma amostra não probabilística, uma vez que é desconhecida a probabilidade de qualquer participante ser incluído na amostra, sendo que ela se caracteriza como conveniente, pois é constituída por indivíduos facilmente acessíveis e que respondem a determinados critérios de inclusão tendo em conta a sua presença em determinado local e momento (FORTIN, 2006).

$\mathrm{O}$ critério de inclusão inerente ao estudo foi a participação de terapeutas ocupacionais que tivessem experiência profissional em CP.

$\mathrm{Na}$ amostra, composta por 15 terapeutas ocupacionais ( $\mathrm{N}=15)$, verificou-se que $93,3 \%(\mathrm{~N}=14)$ dos participantes eram do género feminino e $6,7 \%$ $(\mathrm{N}=1)$ do género masculino, com idades compreendidas entre os 22 e os 60 anos, perfazendo uma média de 34,13 anos de idade, dos quais 40\% ( $\mathrm{N}=6)$ dos participantes apresentavam como habilitações literárias o Bacharelato em terapia ocupacional e
$60 \%(\mathrm{~N}=9)$ dos participantes a Licenciatura em terapia ocupacional. Do total da amostra, 33,3\% $(\mathrm{N}=5)$ dos participantes não apresentavam nenhuma formação nesta área de prática clínica. Os restantes $66,7 \%(\mathrm{~N}=10)$ participantes tinham formação em $\mathrm{CP}$.

Relativamente à coleta de dados, visto que não existiam questionários ou instrumentos de coleta de dados para aplicar aos terapeutas ocupacionais e que avaliassem as metodologias utilizadas por estes profissionais nos $\mathrm{CP}$, tornou-se necessário a construção de um questionário, com vista a responder às necessidades particulares (FORTIN, 2006). Dada a natureza do estudo, tornou-se importante não restringir os terapeutas ocupacionais apenas às respostas do questionário e para tal, através de questôes abertas, os participantes tiveram a possibilidade de expor outras respostas (FORTIN, 2006). Todas as questóes foram formuladas de acordo com o objetivo do estudo, pesquisas bibliográficas efetuadas e por meio do contacto com o orientador e co-orientador do projeto.

O questionário foi autoadministrado (FORTIN, 2006) pelos terapeutas ocupacionais e criado na aplicação Google Docs, de forma a facilitar o preenchimento e reenvio deste para o principal investigador do projeto, estando disponível em formato digital, através de hiperligação. Foi construído um questionário misto, com questóes abertas e questóes fechadas. No caso das questóes, fechadas foram utilizadas questóes dicotómicas (em que o participante teve de escolher entre duas respostas, nomeadamente sim ou não), questóes de escolha múltipla (que comportaram uma série de respostas colocadas em determinada ordem), questóes de enumeração gráfica (em que foi utilizada a Escada de Likert, que consistiu em pedir aos participantes que indicassem o grau de importância em relaçáo à intervenção do terapeuta ocupacional) e questóes-filtro (com o objetivo de dirigir o participante para as questóes que se aplicam à sua situação).

Os peritos foram selecionados tendo em conta o critério de seleçấo estabelecido (terapeutas ocupacionais com experiência profissional em CP) e contactados por e-mail. Após confirmaçáo dos terapeutas ocupacionais, o grupo de peritos foi constituído por três terapeutas ocupacionais, autores/coautores do livro Reabilitação em Cuidados Paliativos, lançado em junho de 2014. $\mathrm{O}$ grupo de peritos fez algumas sugestóes e foram reformuladas e adicionadas mais três questóes abertas ao questionário. O questionário é constituído por 21 questôes (Parte I - Dados Sociodemográficos por 7 questôes; Parte II - Questôes abertas e questôes fechadas por 14 questôes). 
O pré-teste é a prova que consiste em verificar a eficácia e o valor do questionário (FORTIN, 2006). Procedeu-se à aplicação do pré-teste do questionário a dois terapeutas ocupacionais, em que não surgiram dificuldades no preenchimento ou correçôes a impor. Os profissionais incluídos no pré-teste foram incluídos na amostra.

Após a recolha dos e-mails dos terapeutas ocupacionais com experiência profissional em CP, o instrumento de coleta de dados foi enviado para dezasseis terapeutas ocupacionais. Este foi posteriormente disponibilizado online na mailing list de terapia ocupacional e mailing list de CP, ambos constituídos por grupos de subscritores que divulgam e partilham assuntos inerentes à profissão/área de prática clínica comum, bem como no grupo de terapeutas ocupacionais em CP no Facebook, constituído maioritariamente por terapeutas ocupacionais com uma forte ligação à área dos CP. Estes procedimentos de divulgação do questionário possibilitaram o envio deste a 38 terapeutas ocupacionais, na sua totalidade. Após o envio e divulgação do questionário, foi possível reunir 15 questionários preenchidos. Apenas um questionário não foi devidamente preenchido e foi contactado o terapeuta ocupacional, de forma a solicitar o preenchimento dos campos em falta.

A análise dos dados estatísticos foi realizada com recurso ao $\mathrm{SPSS}^{\oplus}$ V.22. Esta foi validada, através do contacto com um docente da Escola Superior de Saúde de Beja (ESSB), com conhecimento na área da estatística. No SPSS $^{\bullet}$ V.22 foram colocadas as respostas de 11 questóes fechadas. A análise das respostas às questôes abertas foi feita com recurso à análise de conteúdo, em que, segundo Bardin (2010), o analista trabalha com palavras que, isoladas, podem atribuir relaçóes com a mensagem ou possibilitar que se faça inferência de conhecimento a partir da mensagem. São estabelecidas correspondências entre as estruturas linguísticas ou semânticas e as estruturas dos enunciados. A leitura do pesquisador responsável pela análise não é, portanto, uma leitura à letra, mas o realçar de um sentido que se encontra em segundo plano.

Para descrever os processos estatísticos foi utilizado o Windows 7, como software do computador. $\mathrm{Na}$ análise de conteúdo foi necessário o Microsoft Office 2013 (Word) como processador de texto, de forma a facilitar o processo de análise.

No projeto de investigação recorreu-se à análise descritiva com o objetivo de identificar as metodologias de intervençấo que os terapeutas ocupacionais utilizam nos $\mathrm{CP}$, onde está subjacente o método de investigaçáo qualitativo e quantitativo, ou seja, uma investigação de cariz misto (FORTIN,
2006). A investigação qualitativa tem por objetivo a compreensão alargada dos fenómenos. No que diz respeito à análise quantitativa, esta visa, sobretudo, explicar e predizer um fenómeno pela medida das variáveis e pela análise de dados numéricos (FORTIN, 2006).

$\mathrm{Na}$ análise qualitativa, foi realizada a análise de conteúdo, segundo a técnica de Bardin (2010), sendo esta dividida em 3 fases:

1) Pré-análise (Fase em que se organiza o material a ser analisado, com o objetivo de o tornar operacional, sistematizando as ideias iniciais. Assim, trata-se da organizaçấo por meio de quatro etapas: a) leitura flutuante para conhecimento do texto, b) escolha dos documentos, onde se demarca o que será analisado, c) formulação de objetivos, d) referenciação e determinação dos indicadores);

2) Exploração do Material (Fase em que se realiza a exploração do material com a definição de categorias (sistemas de codificação), identificação das Unidades de Registo e Unidades de Contexto. Esta fase visa possibilitar a riqueza das interpretaçôes e inferências. É uma fase de descrição analítica);

3) Tratamento dos Resultados, Inferência e Interpretação (Fase destinada ao tratamento dos resultados onde ocorre a condensação e o destaque as informaçóes para análise, culminando nas interpretaçóes inferenciais e análise reflexiva e crítica).

Na primeira fase, Pré-análise, foi organizado o material a ser analisado, seguindo os procedimentos supracitados. Na segunda fase, Exploração do Material, procedeu-se à categorização e identificação das Unidades de Registo e Unidades de Contexto, tendo em conta os pressupostos de Bardin (2010). Desta forma, a Análise de Conteúdo trabalha com mensagens e tem como objetivo a manipulação destas para evidenciar os indicares que permitem inferir sobre uma outra realidade. Para tal, a categorização dos itens foi realizada segundo os critérios definidos por Bardin (2010) que assentam nas características semânticas, sintáticas, léxicas e expressivas. O mesmo autor defende ainda que, para serem consideradas boas categorias, estas devem apresentar qualidades como a exclusão mútua, objetividade e fidelidade, pertinência e produtividade. De acordo com o mesmo autor, as categorias podem ser criadas a priori ou a posteriori, isto é, a partir apenas da teoria ou após a coleta de dados. Nesta análise optou-se 
por categorizar após a coleta de dados, e em todo o processo de construção de categorias procurou-se preservar as ideias-chave transmitidas no questionário.

\section{Resultados e Discussão}

Tendo em consideraçáo os pressupostos defendidos por Bardin (2010), em todo o processo de construçáo de categorias procurou-se preservar as ideias-chave transmitidas no questionário, apresentando-se estas nas tabelas que se seguem. $\mathrm{Na}$ Tabela 1 serão apresentados os resultados relativos à questão "Como considera a intervenção do terapeuta ocupacional com clientes em Cuidados Paliativos?”.

Através da observação da Tabela 1, verificou-se a subcategorização de quatro áreas de intervenção, consideradas importantes para os participantes, nomeadamente a "Promoçáo de autonomia e independência", "Promoção de qualidade de vida", "Promoçáo da resiliência" e "Intervenção com os familiares". É de realçar que 78,6\% (N=11) dos participantes consideraram a subcategoria "Promoção da resiliência", nomeadamente a Unidade de registo "Dar suporte emocional", e 71,4\% (N=10) dos participantes consideraram a subcategoria "Promoção da resiliência", nomeadamente a Unidade de Registo "Promover o envolvimento em atividades significativas" como uma intervenção a pôr em prática com o cliente em CP. A Unidade de Registo "Graduar" apresentou uma percentagem de $28,6 \%(\mathrm{~N}=4)$, sendo a percentagem mais baixa das Unidades de Registo.

Por outro lado, observou-se uma percentagem de 42,9\% (N=6) na subcategoria "Intervenção com familiares e/ou cuidadores”, apesar da questão estar direcionada para os clientes. Esta percentagem vai ao encontro da definição de $\mathrm{CP}$, onde é referido o auxílio da família a lidar pacientemente durante a doença e no próprio luto e às abordagens mais usadas na terapia ocupacional (ASSOCIAÇÃO..., 2014), em que é realizado o ensino aos cuidadores (ARMITRAGE, 1999 apud OLIVEIRA, 2008).

$\mathrm{Na}$ Tabela 2 serão apresentadas as respostas relativas à questão "Como considera a intervenção do terapeuta ocupacional com as famílias de clientes em Cuidados Paliativos?".

Tabela 1. Questão "Como considera a intervenção do terapeuta ocupacional com clientes em Cuidados Paliativos?".

\begin{tabular}{|c|c|c|c|c|c|}
\hline Categoria & Subcategoria & Unidade de registo & Unidade de Contexto & $\mathbf{N}$ & $\%$ \\
\hline \multirow{6}{*}{$\begin{array}{l}\text { Importância } \\
\text { da } \\
\text { intervenção } \\
\text { da terapia } \\
\text { ocupacional } \\
\text { com clientes } \\
\text { em CP }\end{array}$} & \multirow{2}{*}{$\begin{array}{l}\text { Promoção de } \\
\text { autonomia e } \\
\text { independência }\end{array}$} & $\begin{array}{l}\text { Diminuir a } \\
\text { sintomatologia }\end{array}$ & $\begin{array}{l}\text { "Realizar técnicas não medicamentosas } \\
\text { para controlar a sintomatologia }[\ldots . \text { ]", } \\
\text { "Controlar a sintomatologia }[\ldots] \text { ". "Ajudar } \\
\text { o cliente a enfrentar e a adaptar-se à } \\
\text { sintomatologia }[\ldots] \text { ". }\end{array}$ & 8 & 57,1 \\
\hline & & Adaptar & $\begin{array}{l}\text { "Adaptar quando necessário o contexto } \\
{[\ldots] \text { ".., "Adaptar a vida às limitações }} \\
\text { existentes }[\ldots] ", \text { " “[...] confeção de } \\
\text { adaptações". }\end{array}$ & 6 & 42,9 \\
\hline & \multirow{3}{*}{$\begin{array}{l}\text { Promoção de } \\
\text { qualidade de vida } \\
\text { Promoção da } \\
\text { resiliência }\end{array}$} & Graduar & $\begin{array}{l}\text { "Graduar o grau de dificuldade }[\ldots] \text { "., } \\
\text { "Adaptar as atividades necessárias }[\ldots] \text { ", } \\
\text { "[...] sentidos e através destes estabelecer } \\
\text { vias de comunicação". }\end{array}$ & 4 & 28,6 \\
\hline & & $\begin{array}{l}\text { Promover o } \\
\text { envolvimento } \\
\text { em atividades } \\
\text { significativas }\end{array}$ & $\begin{array}{l}\text { "Realizar projetos pessoais; Realizar } \\
\text { aspirações pessoais", "Garantir a } \\
\text { satisfação das atividades [...]", "Criar } \\
\text { situações de promoção de ocupações } \\
\text { significativas [...]". }\end{array}$ & 10 & 71,4 \\
\hline & & $\begin{array}{l}\text { Dar suporte } \\
\text { emocional }\end{array}$ & $\begin{array}{l}\text { "Realizar um acompanhamento mais } \\
\text { psicológico }[\ldots] ", \text { "Promover reencontros } \\
\text { com desafetos }[\ldots] \text { ", "Proporcionar o } \\
\text { grito de dor }[\ldots] " \text {. }\end{array}$ & 11 & 78,6 \\
\hline & $\begin{array}{l}\text { Intervenção com } \\
\text { familiares e/ou } \\
\text { cuidadores }\end{array}$ & $\begin{array}{l}\text { Aconselhamento/ } \\
\text { Facilitar estratégias }\end{array}$ & $\begin{array}{l}\text { "Auxiliar os cuidadores no tipo de ajuda } \\
\text { que deve ser dada }[\ldots] \text {..." "[...] como se } \\
\text { devem proteger no cuidado ao outro", } \\
\text { "Realizar uma intervenção voltada para } \\
\text { a família e cuidadores [...]". }\end{array}$ & 6 & 42,9 \\
\hline
\end{tabular}

$\mathrm{N}=14$. 
Tabela 2. Questão "Como considera a intervenção do terapeuta ocupacional com as famílias de clientes em Cuidados Paliativos?".

\begin{tabular}{|c|c|c|c|c|c|}
\hline Categoria & Subcategoria & Unidade de Registo & Unidade de Contexto & $\mathbf{N}$ & $\%$ \\
\hline \multirow{5}{*}{$\begin{array}{l}\text { Importância } \\
\text { da } \\
\text { intervenção } \\
\text { da terapia } \\
\text { ocupacional } \\
\text { com } \\
\text { famílias de } \\
\text { clientes em } \\
\text { CP }\end{array}$} & \multirow{3}{*}{ Acolhimento } & $\begin{array}{l}\text { Acolher em todas as } \\
\text { fases da doença }\end{array}$ & $\begin{array}{l}\text { "Acolher as famílias antes da sua } \\
\text { orientação }[\ldots] " \text { ". "Acolher as famílias } \\
\text { em todas as fases inclusive no pós-óbito } \\
{[\ldots] \text { ", "Estar presente, em todos os }} \\
\text { momentos [...] e demais acolhimentos". }\end{array}$ & 5 & 35,7 \\
\hline & & $\begin{array}{l}\text { Partilha de } \\
\text { sentimentos }\end{array}$ & $\begin{array}{l}\text { "Promover a partilha de sentimentos } \\
\text { de aceitação", "Escuta ativa", "[...] } \\
\text { Partilha no pré e pós-luto [...]". }\end{array}$ & 11 & 78,6 \\
\hline & & Dar suporte & $\begin{array}{l}\text { "Ajudar a família a enfrentar a doença } \\
\text { do seu familiar", "Dar suporte para } \\
\text { ajudar a família a enfrentar o momento } \\
\text { do adoecimento [...]", "Evitar lutos } \\
\text { patológicos". }\end{array}$ & 7 & 50 \\
\hline & \multirow[t]{2}{*}{ Aconselhamento } & Orientar & $\begin{array}{l}\text { "Orientar o cuidador acerca dos cuidados } \\
\text { específicos [...]", "Orientar os cuidadores } \\
\text { sobre como lidar/auxiliar o cliente [...]", } \\
\text { "Orientar as famílias em relação ao } \\
\text { cuidado com o cliente". }\end{array}$ & 8 & 57,1 \\
\hline & & Adaptar & $\begin{array}{l}\text { "Reorganizar a vida das famílias [...]", } \\
\text { "Adaptar a rotina de todos à situação } \\
\text { adquirida [...]", "Adequar os cuidados } \\
\text { às necessidades do cliente". }\end{array}$ & 5 & 35,7 \\
\hline
\end{tabular}

$\mathrm{N}=14$.

Através da observação da Tabela 2, é de salientar que $78,6 \%(\mathrm{~N}=11)$ dos participantes consideraram a subcategoria "Acolhimento", nomeadamente a Unidade de Registo "Partilha de sentimentos", como uma intervenção a utilizar com as famílias de clientes em CP. Por outro lado, verificou-se que $35,7 \%(\mathrm{~N}=5)$ dos participantes consideraram as Unidades de Registo "Adaptar" e "Acolher em todas as fases da doença" como uma intervenção com as famílias de clientes em CP, apresentando as percentagens mais baixas das Unidades de Registo.

Verificou-se que a intervenção com as famílias está direcionada, segundo as Unidades de Registo, para "Acolher em todas as fases da doença" através de Unidades de Contexto como "Estar presente em todos os momentos", "Partilha de sentimentos" através de Unidades de Contexto como "Promover a partilha de sentimentos de aceitação", "Dar suporte" através de Unidades de Contexto como "Dar suporte para ajudar a família a enfrentar o momento do adoecimento", "Orientar" através de Unidades de Contexto como "Orientar as famílias em relação ao cuidado com o cliente" e "Adaptar" através de Unidades de Contexto como "Adaptar a rotina de todos à situação adquirida", indo ao encontro dos mesmos autores supracitados na discussão dos resultados referentes à Tabela 1 .

$\mathrm{Na}$ Tabela 3 serão apresentadas as respostas relativas à questão "Como considera a intervenção do terapeuta ocupacional com outros técnicos de Saúde (psicólogo, enfermeiro, médico, entre outros) nos Cuidados Paliativos?".

Através da observação da Tabela 3, destacou-se a percentagem de $92,9 \%(\mathrm{~N}=13)$ de participantes na subcategoria "Intervenção do terapeuta ocupacional na equipa de CP", nomeadamente na Unidade de Registo "Abordagens de intervenção do terapeuta ocupacional". A percentagem de 42,9\% ( $\mathrm{N}=6)$ na Unidade de Registo "Partilha de experiências" apresentou a percentagem mais baixa das Unidades de Registo relativas à importância da intervenção do terapeuta ocupacional com outros técnicos de Saúde nos CP.

$\mathrm{Na}$ Tabela 4 serão apresentadas as respostas relativas à questão "Que tipo de abordagens utiliza na intervenção em Cuidados Paliativos? E por quê?”.

Através da observação Tabela 4, verificou-se a subcategorização de duas áreas de intervenção, consideradas como importantes para os participantes, nomeadamente a Intervenção com a "Família" e com o próprio "Cliente". Na subcategoria "Família", destacaram-se as Unidades de Registo "Educação" com uma percentagem de $71,4 \%(\mathrm{~N}=10)$ dos participantes e "Orientaçáo" e "Aconselhamento" com uma percentagem de 64,3\% (N=9) dos participantes. Na subcategoria "Cliente", verificaram-se as Unidades de Registo "Promover envolvimento 
Tabela 3. Questão "Como considera a intervenção do terapeuta ocupacional com outros técnicos de Saúde (psicólogo, enfermeiro, médico, entre outros) nos Cuidados Paliativos?".

\begin{tabular}{|c|c|c|c|c|c|}
\hline Categoria & Subcategoria & Unidade de Registo & Unidade de Contexto & $\mathbf{N}$ & $\%$ \\
\hline \multirow{3}{*}{$\begin{array}{l}\text { Importância } \\
\text { da } \\
\text { intervenção } \\
\text { da terapia } \\
\text { ocupacional } \\
\text { com outros } \\
\text { técnicos de } \\
\text { saúde em } \\
\text { CP }\end{array}$} & \multirow[t]{2}{*}{ Equipa de CP } & $\begin{array}{l}\text { Partilha de } \\
\text { informação }\end{array}$ & $\begin{array}{l}\text { "Partilhar a informação de forma a } \\
\text { oferecer cuidados integrais ao cliente } \\
\text { e família [...]", "Partilhar informações } \\
\text { para que todos os profissionais tenham as } \\
\text { mesmas informações [...]", "Estabelecer } \\
\text { rotinas para intervenções individuais dos } \\
\text { profissionais [...]". }\end{array}$ & 8 & 57,1 \\
\hline & & $\begin{array}{l}\text { Partilha de } \\
\text { experiências }\end{array}$ & $\begin{array}{l}\text { "Compartilhar experiências bem-sucedidas } \\
\text { ou não", "Transmitir conhecimentos [...]", } \\
\text { "A relação e interação [...] são essenciais, } \\
\text { pois existem aspetos do domínio e áreas } \\
\text { profissionais específicas [...]". }\end{array}$ & 6 & 42,9 \\
\hline & $\begin{array}{l}\text { Intervenção do TO } \\
\text { na equipa de CP }\end{array}$ & $\begin{array}{l}\text { Abordagens de } \\
\text { intervenção do TO }\end{array}$ & $\begin{array}{l}\text { "Apoiar o cliente em todas as vertentes, } \\
\text { visando sempre o cliente como um ser } \\
\text { holístico", "Ajudar o cliente a encontrar o } \\
\text { alívio da dor e sofrimento", "Melhorar a } \\
\text { qualidade de vida [...]", “[...] reforçando } \\
\text { a importância do cliente e dos seu papéis } \\
\text { e atividades significativas [...]", "[...] } \\
\text { conhecimentos em nível de estimulação } \\
\text { sensorial e da integração sensorial [...]". }\end{array}$ & 13 & 92,9 \\
\hline
\end{tabular}

$\mathrm{N}=14$.

em atividades significativas" e "Utilizar técnicas de intervenção específicas” com uma percentagem de $85,8 \%(\mathrm{~N}=12)$ dos participantes, e a subcategoria "Relação terapêutica" com uma percentagem de $78,6 \%(\mathrm{~N}=11)$ dos participantes. A percentagem mais baixa apresentou-se nas Unidades de Registo "Acolhimento" de ambas as subcategorias com uma percentagem de 28,6\% ( $\mathrm{N}=4)$ dos participantes. Verificou-se que as Unidades de Registo "Relação terapêutica", "Acolhimento", "Partilha de informação", "Aconselhamento", "Educação", "Orientar", Avaliação", "Educação e Treino", "Promover o envolvimento nas atividades significativas", "Adaptar e/ou Graduar" e "Utilizar técnicas de intervenção específicas" vão ao encontro das abordagens supracitadas na discussáo dos resultados da Tabela 1 por Costa e Othero (2014), em que as abordagens mais usadas são o treino e orientação, massagem e exercícios de alívio e controlo da dor, orientaçấo para a facilitação, estímulos de atividades físicas, preservar o grau de independência, ensino aos cuidadores, confeção de adaptaçôes e realização de atividades terapêuticas (OLIVEIRA, 2008). A função dos terapeutas ocupacionais nos $\mathrm{CP}$ direciona-se à promoção do envolvimento da pessoa em atividades funcionais para o tratamento, adaptação, treino, orientação e controlo da dor.

$\mathrm{Na}$ Tabela 5 serão apresentadas as respostas relativas à questáo "Do seu ponto de vista, existem outras abordagens/metodologias que poderiam ser utilizadas na intervenção em Cuidados Paliativos? Se sim, quais?".

Através da observação da Tabela 5, verificaram-se duas subcategorias, nomeadamente "Sugestóes de abordagens/técnicas" e "Sem sugestôes". Os resultados mostraram que $53,3 \%(\mathrm{~N}=8)$ dos participantes não sugerem outras abordagens/técnicas inerentes à prática nos CP. Em relação à subcategoria "Sugestōes de abordagens/técnicas", foram criadas três unidades de Registo, destacando-se a percentagem de 33,3\% $(\mathrm{N}=5)$ dos participantes na Unidade de Registo "Com o cliente". A percentagem mais baixa apresentou-se na Unidade de Registo "Com a equipa" com a percentagem de $13,3 \%(\mathrm{~N}=2)$ dos participantes.

Verificou-se que $47,7 \%(\mathrm{~N}=7)$ dos participantes sugeriram outras abordagens/metodologias na intervenção em $\mathrm{CP}$, como é possível analisar através das Unidades de Registo "Com o cliente", "Com a família" e "Respostas Sociais". Estes resultados obtidos na Tabela 5, vão ao encontro dos estudos de Henning (2010) e da APCP (ASSOCIAÇÃO..., 2014), onde são referidos que os cuidados não estão ao alcance de todos os clientes, e apesar de terem surgido algumas iniciativas e progressos no âmbito do desenvolvimento nos $\mathrm{CP}$, estes ainda se encontram longe do que seria ambicionado.

$\mathrm{Na}$ Tabela 6 serão apresentadas as respostas relativas à questão "Em Cuidados Paliativos, quais os resultados que o terapeuta vê na sua intervençáo com clientes e famílias?”. 
Tabela 4. Questão "Que tipo de abordagens utiliza na intervenção em Cuidados Paliativos? E por quê?".

\begin{tabular}{|c|c|c|c|c|c|}
\hline Categoria & Subcategoria & Unidade de Registo & Unidade de Contexto & $\mathbf{N}$ & $\%$ \\
\hline \multirow{13}{*}{$\begin{array}{l}\text { Tipo de } \\
\text { abordagens } \\
\text { utilizadas } \\
\text { pelos } \\
\text { terapeutas } \\
\text { ocupacionais } \\
\text { nos CP }\end{array}$} & \multirow{6}{*}{ Família } & Relação terapêutica & $\begin{array}{l}\text { "[...] privilegiando as relações interpessoais", } \\
\text { "A relação é o mais importante }[\ldots] \text {..., "[...] } \\
\text { tudo decorre da relação". }\end{array}$ & 7 & 50 \\
\hline & & Acolhimento & “Acolhimento à família [...]”. & 4 & 28,6 \\
\hline & & $\begin{array}{l}\text { Partilha de } \\
\text { informação }\end{array}$ & $\begin{array}{l}\text { "Escuta ativa", "Exploração da rotina e } \\
\text { do impacto da doença no cuidador [...]" }\end{array}$ & 6 & 42,9 \\
\hline & & Aconselhamento & $\begin{array}{l}\text { "[...] aconselhamento, produtos apoio } \\
{[\ldots] " \text { " "[...] informação de exercícios que }} \\
\text { o doente deve realizar e as atividades que } \\
\text { o deve deixar continuar". }\end{array}$ & 9 & 64,3 \\
\hline & & Educação & $\begin{array}{l}\text { "Ensino de transferências", "Ensino de } \\
\text { posicionamento". }\end{array}$ & 10 & 71,4 \\
\hline & & Orientar & $\begin{array}{l}\text { "Orientação", "Orientar a família [...]", "É } \\
\text { importante orientar o cliente ou familiar } \\
\text { [...]". }\end{array}$ & 9 & 64,3 \\
\hline & \multirow{7}{*}{ Cliente } & Relação terapêutica & $\begin{array}{l}\text { "Abordagem humanista", "[...] privilegiando } \\
\text { as relações interpessoais", "Escuta [...]", } \\
\text { "A relação é o mais importante [...]". }\end{array}$ & 11 & 78,6 \\
\hline & & Acolhimento & $\begin{array}{l}\text { "O acolhimento é fundamental ouvir o que } \\
\text { o cliente tem para dizer }[\ldots] ", \text { "[...] estar } \\
\text { disponível para acolhê-lo". }\end{array}$ & 4 & 28,6 \\
\hline & & Avaliação & $\begin{array}{l}\text { "[...] avaliação no qual incluía a anamnese", } \\
\text { "[...] avaliação de interesses e papéis } \\
\text { através de checklists", "[...] avaliações } \\
\text { do desempenho }[\ldots] " .\end{array}$ & 8 & 57,1 \\
\hline & & Educação e Treino & 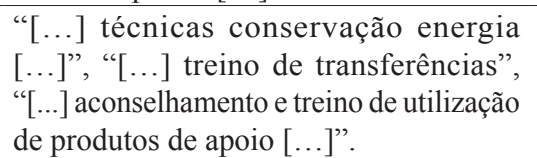 & 9 & 64,3 \\
\hline & & $\begin{array}{l}\text { Promover } \\
\text { envolvimento } \\
\text { nas atividades } \\
\text { significativas }\end{array}$ & $\begin{array}{l}\text { "[...] atividades significativas", "[...] gostos, } \\
\text { interesses, necessidades do cliente e/ou } \\
\text { família dependia o tipo de intervenção", } \\
\text { "Abordagem eclética". }\end{array}$ & 12 & 85,8 \\
\hline & & $\begin{array}{l}\text { Adaptar e/ou } \\
\text { Graduar }\end{array}$ & $\begin{array}{l}\text { "Adaptação e graduação }[\ldots] ", \text { " "[...] } \\
\text { estratégias compensatórias [...]", } \\
\text { "Atendimentos em grupo ou individuais } \\
{[\ldots] . "}\end{array}$ & 7 & 50 \\
\hline & & $\begin{array}{l}\text { Utilizar técnicas } \\
\text { de intervenção } \\
\text { especifícas }\end{array}$ & $\begin{array}{l}\text { "[...] estimulação sensorial }[\ldots] ”, \text { " "[...] } \\
\text { treino de AVD's", "[ ...] recursos percetivo- } \\
\text { sensoriais". }\end{array}$ & 12 & 85,8 \\
\hline
\end{tabular}

$\mathrm{N}=14$.

Na observação da Tabela 6, a subcategorização das quatro áreas de intervenção, consideradas como importantes para os participantes, vão ao encontro das referidas na Tabela 3, uma vez que os resultados estão relacionados com os objetivos e importância da intervenção do terapeuta ocupacional nos CP, optando-se pela mesma subcategorização. Destacaram-se as Unidades de Registo "Aconselhamento/Facilitar estratégias" com uma percentagem de $92,9 \%(\mathrm{~N}=13)$ dos participantes, "Dar suporte emocional" com uma percentagem de 100\% (N=14) e "Diminuir a sintomatologia" com uma percentagem de $85,7 \%$ $(\mathrm{N}=12)$ dos participantes. Por outro lado, a Unidade de registo "Adaptar" apresentou a percentagem mais baixa com $21,4 \%(\mathrm{~N}=3)$ dos participantes.

Verificou-se uma congruência entre os resultados obtidos na Tabela 6 e na Tabela 1, onde foram estabelecidas Unidades de registo iguais e as posiçóes defendidas por Burkhardt et al. (2011), Oliveira (2008) e Costa e Othero (2014) supracitadas anteriormente, uma vez que os objetivos que se pretendem atingir (Tabela 1) vão ao encontro dos resultados obtidos na intervenção dos profissionais (Tabela 6).

$\mathrm{Na}$ Tabela 7 serão apresentados as respostas relativas à questão "Como considera a evolução 
Tabela 5. Questão "Do seu ponto de vista, existem outras abordagens/metodologias que poderiam ser utilizadas na intervenção em Cuidados Paliativos? Se sim, quais?”.

\begin{tabular}{|c|c|c|c|c|c|}
\hline Categoria & Subcategoria & $\begin{array}{l}\text { Unidade de } \\
\text { Registo }\end{array}$ & Unidade de Contexto & $\mathbf{N}$ & $\%$ \\
\hline \multirow{4}{*}{$\begin{array}{l}\text { Outras } \\
\text { abordagens/ } \\
\text { metodologias } \\
\text { que poderiam } \\
\text { ser utilizadas } \\
\text { na intervenção } \\
\text { em Cuidados } \\
\text { Paliativos }\end{array}$} & \multirow{3}{*}{$\begin{array}{l}\text { Sugestões de } \\
\text { abordagens/ } \\
\text { técnicas }\end{array}$} & Com o cliente & $\begin{array}{l}\text { "O Modelo de Ocupação Humana pode } \\
\text { ser bastante útil [...]", "Abordagem } \\
\text { Reabilitativa, Abordagem Psicossocial, } \\
\text { Abordagem Interativa de Grupos". }\end{array}$ & 5 & 33,3 \\
\hline & & Com a equipa & $\begin{array}{l}\text { "No meu caso, haver equipa multidisciplinar } \\
{[\ldots] \text { ".., "[...] profissionais mais voltados à }} \\
\text { questões e técnicas de reabilitação física". }\end{array}$ & 2 & 13,3 \\
\hline & & Respostas Sociais & $\begin{array}{l}\text { "[...] integração com redes de apoio na } \\
\text { comunidade","Acesso a alimentos [...]", } \\
\text { "Poder na tomada de decisão [...]". }\end{array}$ & 3 & 20 \\
\hline & Sem sugestões & & & 8 & 53,3 \\
\hline
\end{tabular}

$\mathrm{N}=15$.

Tabela 6. Questão "Em Cuidados Paliativos, quais os resultados que o terapeuta vê na sua intervenção com clientes e famílias?".

\begin{tabular}{|c|c|c|c|c|c|}
\hline Categoria & Subcategoria & Unidade de Registo & Unidade de Contexto & $\mathbf{N}$ & $\%$ \\
\hline \multirow{5}{*}{$\begin{array}{l}\text { Resultados } \\
\text { da } \\
\text { intervenção } \\
\text { da terapia } \\
\text { ocupacional } \\
\text { em CP }\end{array}$} & \multirow{2}{*}{$\begin{array}{l}\text { Promoção de } \\
\text { autonomia e } \\
\text { independência }\end{array}$} & $\begin{array}{l}\text { Diminuir a } \\
\text { sintomatologia }\end{array}$ & $\begin{array}{l}\text { "[...] redução da dor, da ansiedade, depressão } \\
\text { [...]", "Diminuição de sintomas, como dor, } \\
\text { fadiga, dificuldades respiratórias, edema". }\end{array}$ & 12 & 85,7 \\
\hline & & Adaptar & $\begin{array}{l}\text { "[...] as mudanças nos contextos e } \\
\text { desempenho ocupacional }[\ldots] " \text {. }\end{array}$ & 3 & 21,4 \\
\hline & $\begin{array}{l}\text { Promoção de } \\
\text { qualidade de vida }\end{array}$ & $\begin{array}{l}\text { Promover o } \\
\text { envolvimento } \\
\text { em atividades } \\
\text { significativas }\end{array}$ & $\begin{array}{l}\text { "[...] ir de encontro aos interesses do } \\
\text { cliente", "Possibilidade de realizar os } \\
\text { últimos "desejos' e projetos". }\end{array}$ & 11 & 78,6 \\
\hline & $\begin{array}{l}\text { Promoção da } \\
\text { resiliência }\end{array}$ & $\begin{array}{l}\text { Dar suporte } \\
\text { emocional }\end{array}$ & $\begin{array}{l}\text { "[...] pacificação nos relacionamentos } \\
\text { e com a vida", "Melhor enfrentamento } \\
\text { do adoecimento", "Melhor aceitação do } \\
\text { processo de doença [...]", “[ ...] bem-estar } \\
\text { do cliente }[\ldots] \text {.. }\end{array}$ & 14 & 100 \\
\hline & $\begin{array}{l}\text { Intervenção com } \\
\text { familiares e/ou } \\
\text { cuidadores }\end{array}$ & $\begin{array}{l}\text { Aconselhamento/ } \\
\text { Facilitar estratégias }\end{array}$ & $\begin{array}{l}\text { "Maior "conforto' na fase da morte e do luto", } \\
\text { "[...] alívio de dor }[\ldots] \text { tanto do cliente, } \\
\text { quanto dos familiares-cuidadores", "[...] } \\
\text { pequenas melhorias na rotina que podem } \\
\text { aumentar a qualidade de vida dos utentes e } \\
\text { familiares","[...] ficam mais esclarecidos } \\
\text { a respeito dos procedimentos realizados e } \\
\text { do prognóstico da doença". }\end{array}$ & 13 & 92,9 \\
\hline
\end{tabular}

$\mathrm{N}=14$.

dos Cuidados Paliativos onde exerceu/exerce a sua prática clínica?

Através da observação da Tabela 7, verificaram-se duas subcategorias, nomeadamente "Existe evolução" e "Sem evoluçáo". Os resultados mostraram que $53,3 \%(\mathrm{~N}=8)$ dos participantes náo sugeriram outras abordagens/técnicas inerentes à prática nos CP. Para cada subcategoria foram criadas três unidades de registo, destacando-se 66,7\% (N=10) dos participantes na Unidade de registo "Equipa" da subcategoria "Existe evolução", e a percentagem de $33,3 \%(\mathrm{~N}=5)$ dos participantes na Unidade de
Registo "Políticas internas" da subcategoria "Sem evolução".

Verificou-se uma evolução, através das percentagens de $66,7 \%(\mathrm{~N}=10)$ na Unidade de registo "Equipa", $33,3 \%(\mathrm{~N}=5)$ na Unidade de registo "Terapia ocupacional" e 26,7\% (N=4) na Unidade de Registo "Políticas internas" que vão ao encontro dos estudos de Henning (2010) e APCP (ASSOCIAÇÃO..., 2014) supracitados na discussão dos resultados da Tabela 5.

A percentagem obtida na Tabela 5, onde $47,7 \%(\mathrm{~N}=7)$ dos participantes sugeriram outras 
Tabela 7. Questão "Como considera a evolução dos Cuidados Paliativos onde exerceu/exerce a sua prática clínica?”.

\begin{tabular}{|c|c|c|c|c|c|}
\hline Categoria & Subcategoria & Unidade de Registo & Unidade de Contexto & $\mathbf{N}$ & $\%$ \\
\hline \multirow{6}{*}{$\begin{array}{l}\text { Evolução } \\
\text { dos CP onde } \\
\text { exerce/ } \\
\text { exerceu } \\
\text { prática } \\
\text { clínica }\end{array}$} & \multirow{3}{*}{$\begin{array}{l}\text { Existe } \\
\text { evolução }\end{array}$} & Terapia ocupacional & $\begin{array}{l}\text { "O reconhecimento dos familiares e dos } \\
\text { pacientes veio primeiro". }\end{array}$ & 5 & 33,3 \\
\hline & & Equipa & $\begin{array}{l}\text { "A equipa não tem formação em CP [...], } \\
\text { porém são obstáculos superados diariamente", } \\
\text { "[...] maior importância de toda a equipa } \\
\text { com a intervenção do terapeuta ocupacional } \\
{[\ldots] \text { "... "[...] prática mais abrangente e }} \\
\text { baseada nos princípios de trabalho em } \\
\text { equipa multidisciplinar }[\ldots] " .\end{array}$ & 10 & 66,7 \\
\hline & & Politicas internas & $\begin{array}{l}\text { "Administração }[\ldots] \text { flexibilizar algumas } \\
\text { políticas do serviço", "[...] reestruturação } \\
\text { do serviço", "[...] aumento do número de } \\
\text { profissionais }[\ldots] " \text {. }\end{array}$ & 4 & 26,7 \\
\hline & \multirow{3}{*}{$\begin{array}{l}\text { Sem } \\
\text { evolução }\end{array}$} & $\begin{array}{l}\text { Terapeuta } \\
\text { ocupacional }\end{array}$ & $\begin{array}{l}\text { "[...] refletirmos sobre a intervenção } \\
\text { sistemática padrão ou sugerida de atuação } \\
\text { da terapia ocupacional". }\end{array}$ & 1 & 6,7 \\
\hline & & $\begin{array}{l}\text { Intervenção em } \\
\text { equipa }\end{array}$ & $\begin{array}{l}\text { "O trabalho em equipa multidisciplinar } \\
\text { continua a ser uma miragem", "Assiste-se } \\
\text { a uma hegemonia de grupos profissionais } \\
\text { com receio da entrada ou participação de } \\
\text { outros". }\end{array}$ & 3 & 20 \\
\hline & & Políticas internas & $\begin{array}{l}\text { "Indicar para CP no diagnóstico", "Considerar } \\
\text { os Cuidados Paliativos desde o diagnóstico } \\
\text { de uma doença potencialmente fatal e não } \\
\text { apenas na fase terminal", "Estimular a } \\
\text { desospitalização", "[...] falha na questão de } \\
\text { protocolos ou instrumentos específicos [...]". }\end{array}$ & 5 & 33,3 \\
\hline
\end{tabular}

$\mathrm{N}=15$.

abordagens/metodologias na intervenção em CP, através das Unidades de Registo "Com o cliente", "Com a família" e "Respostas Sociais", relacionam-se com as Unidades de Registo da Tabela 7 "Terapia ocupacional", "Intervenção em equipa" e Políticas internas", onde os participantes referiram náo existir evolução nas unidades de registo supracitadas.

$\mathrm{Na}$ Tabela 8 serão apresentadas as respostas relativas à questáo "Do seu ponto de vista, o que poderá ser feito para divulgar/promover o contributo da intervenção do terapeuta ocupacional nos Cuidados Paliativos?”

Através da observação da Tabela 8 , foram criadas três subcategorias, nomeadamente "Formação Contínua", "Publicaçôes" e "Divulgação". Dada a similitude em termos de semântica, nas Unidades de Contexto foram criadas duas Unidades de Registo que se adequam a todas as subcategorias. Destacou-se a Unidade de registo "Promover o desenvolvimento da terapia ocupacional nos CP" com uma percentagem de $100 \%(\mathrm{~N}=15)$ dos participantes. Em relação à Unidade de registo "Promover a participação na educação", esta apresentou uma percentagem de $73,3 \%(\mathrm{~N}=11)$ dos participantes.
Verificou-se uma percentagem de 100\% (N=15) na Unidade de Registo "Promover o desenvolvimento da terapia ocupacional nos CP" através das subcategorias "Formação contínua", "Publicaçôes" e "Divulgação". No entanto, é possível que 33,3\% $(\mathrm{N}=5)$ dos participantes não apresentassem nenhuma formação em CP, verificando-se uma incongruência entre as percentagens de $20 \%(\mathrm{~N}=3)$ e $6,7 \%(\mathrm{~N}=1)$ obtidas na subcategoria "Sem evolução", referente à questáo da Tabela 7 , uma vez que mostraram os participantes referiram náo haver evolução, mas sugeriram a formação contínua para promover o contributo da intervenção, apesar de 33,3\% (N=5) dos participantes não apresentarem nenhuma formação, embora tivessem prática clínica nos $\mathrm{CP}$.

Através da análise quantitativa, são seguidamente descritos os resultados obtidos nas questóes de enumeração gráfica, apresentadas segundo o modelo da Escala de Likert, com cinco opções (1- Extremamente importante; 2- Muito importante; 3-Importante; 4- Pouco importante; 5 - Sem importância). Nas três questôes, é pedido aos participantes que indiquem o grau de importância em relação à intervençáo do terapeuta ocupacional. 
Tabela 8. Questão "Do seu ponto de vista, o que poderá ser feito para divulgar/promover o contributo da intervenção do terapeuta ocupacional nos Cuidados Paliativos?".

\begin{tabular}{|c|c|c|c|c|c|}
\hline Categoria & Subcategoria & Unidade de Registo & Unidade de Contexto & $\mathbf{N}$ & $\%$ \\
\hline \multirow{2}{*}{$\begin{array}{l}\text { Divulgar/ } \\
\text { Promover o } \\
\text { contributo da } \\
\text { intervenção } \\
\text { da terapia } \\
\text { ocupacional } \\
\text { nos CP }\end{array}$} & Formação contínua & $\begin{array}{l}\text { Promover o } \\
\text { desenvolvimento da } \\
\text { terapia ocupacional } \\
\text { nos CP }\end{array}$ & $\begin{array}{l}\text { "Formações [...]", "[...] procurar } \\
\text { formas de avaliar e validar a atuação", } \\
\text { "Publicação de artigos, livros e trabalhos } \\
\text { científicos [...]", "[...] produzir evidências } \\
\text { cientificas". }\end{array}$ & 15 & 100 \\
\hline & Divulgação & $\begin{array}{l}\text { Promover a } \\
\text { participação na } \\
\text { educação }\end{array}$ & $\begin{array}{l}\text { "[...] mudança de mentalidades", } \\
\text { "Aumentar a participação dos profissionais } \\
\text { da terapia ocupacional nos congressos e } \\
\text { eventos", "Promover a terapia ocupacional } \\
\text { em aulas e eventos institucionais [...]". }\end{array}$ & 11 & 73,3 \\
\hline
\end{tabular}

$\mathrm{N}=15$.

Em relação à questáo "Como considera a intervençáo do terapeuta ocupacional com clientes em Cuidados Paliativos?", verificou-se que 66,7\% $(\mathrm{N}=10)$ dos participantes consideraram a intervenção do terapeuta ocupacional em CP "Extremamente importante", 26\% (N=4) consideraram a intervenção do terapeuta ocupacional em CP "Muito importante" e $6,7 \%(N=1)$ referiram a intervenção do terapeuta ocupacional em CP "Importante".

Em relação à questão "Como considera a intervençâo do terapeuta ocupacional com as famílias de clientes em Cuidados Paliativos?", verificou-se que 60\% $(\mathrm{N}=9)$ dos participantes referiram a intervenção do terapeuta ocupacional em CP "Extremamente importante", 33,3\% $(\mathrm{N}=5)$ consideraram a intervenção do terapeuta ocupacional em CP "Muito importante" e 6,7\% (N=1) referiram a intervenção do terapeuta ocupacional em CP "Sem importância".

Em relação à questão "Como considera a intervenção do terapeuta ocupacional com outros técnicos de Saúde (psicólogo, enfermeiro, médico, entre outros) em Cuidados Paliativos?", verificou-se que 73,3\% $(\mathrm{N}=11)$ dos participantes consideraram a intervenção do terapeuta ocupacional em CP "Extremamente importante", 20\% ( $\mathrm{N}=3)$ referiram a intervenção do terapeuta ocupacional em CP "Muito Importante" e $6,7 \%(\mathrm{~N}=1)$ consideraram a intervençáo do terapeuta ocupacional em CP "Sem importância".

Os resultados obtidos nas três questôes de enumeração gráfica evidenciam a importância da intervenção do terapeuta ocupacional nos $\mathrm{CP}$ e vão ao encontro dos pressupostos defendidos por Costa (2012), Othero (2010) e American Occupational Therapy Association (AMERICAN..., 2008), supracitadas anteriormente, que realçam a importância da intervençấo do profissional de terapia ocupacional nesta área de prática clínica.

\section{Conclusão}

O principal objetivo desta investigação desenvolvida em Portugal foi verificar o contributo da intervençâo da terapia ocupacional nos CP e aprofundar os conhecimentos acerca desta intervenção, através da descriçáo das principais metodologias utilizadas, para uma perceção integral da intervençáo realizada nesta área de prática clínica.

O estudo de investigação permitiu uma reflexão acerca do tema "Contributo da intervenção da terapia ocupacional nos Cuidados Paliativos", onde foi possível verificar como principais metodologias/abordagens a "Promoção da relação terapêutica", "Acolhimento", "Partilha de informação", "Aconselhamento", "Educação", "Orientação" e a importância do papel ativo dos familiares/cuidadores em todo o processo. Foi ainda possível verificar a importância da "Relação terapêutica", "Acolhimento", "Avaliação", "Educação", "Treino", "Promoção do envolvimento nas atividades significativas", "Adaptação/Graduaçáo" e "Utilização de técnicas de intervenção específicas" com o cliente.

Realça-se a congruência nas respostas obtidas pelos terapeutas ocupacionais que desenvolvem a sua intervenção terapêutica na área de prática clínica dos Cuidados Paliativos, relativamente às principais metodologias/abordagens utilizadas.

No que diz respeito às limitaçóes ao estudo, destaca-se a escassez de evidência científica em termos de estudos divulgados e acessíveis acerca da intervenção da terapia ocupacional nos $\mathrm{CP}$, bem como a pequena dimensão da amostra, tendo em conta que não é representativa da população em estudo.

É de realçar a importância do presente estudo como um impulsionador para a promoção do contributo da intervenção da terapia ocupacional, bem como para a sua divulgação, visto não existirem 
estudos que evidenciem a intervenção nesta área de prática clínica.

Os resultados obtidos poderáo ser, simultaneamente, importantes no contributo para a definição de linhas orientadoras para a intervenção da terapia ocupacional nos Cuidados Paliativos.

Tendo em conta que o presente estudo se trata de um estudo descritivo simples, é sugerida a continuidade da investigaçáo do presente tema e, se possível, a correlação entre a intervenção da terapia ocupacional nos $\mathrm{CP}$, o local de prática, formação e os resultados obtidos com a população que necessita da prestação deste tipo de cuidados.

\section{Referências}

AMERICAN OCCUPATIONAL THERAPY ASSOCIATION - AOTA. The role of occupational therapy in end-of-life care. The American Journal of Occupational Therapy, Boston, v. 65, n. SE6, p. 65-75, 2008.

ASSOCIAÇÃO PORTUGUESA DE CUIDADOS PALIATIVOS - APCP. Porto, 2014. Disponível em: <http://www.apcp.com.pt/cuidadospaliativos/oquesao. html>. Acesso em: 20 mar. 2014.

BARDIN, L. Análise de conteúdo. Lisboa: Edições 70, 2010.

BOULAY, D. S. Changin the face of death: the story of Cicley Saunders. Great Britain: Brightsea Press, 2007.

BURKHARDT, A. et al. The role of occupational therapy in end-of-life care. The American Journal of Occupational Therapy, Boston, v. 65, n. SE6, p. 671-675, 2011.

CARLO, M.; QUEIROZ, M. Dor e Cuidados Paliativos: terapia ocupacional e interdisciplinaridade. São Paulo: Roca, 2008.
COSTA, A. Ética e comunicação em Cuidados Paliativos. Hospitalidade, Lisboa, n. 297, p. 26-30, 2012.

COSTA, A.; OTHERO, M. Reabilitação em Cuidados Paliativos. Loures: Lusodidacta, 2014.

ENTIDADE REGULADORA DA SAÚDE - ERS. Avaliação do acesso dos utentes aos cuidados continuados de saúde. Porto, 2013. Disponível em: <https://www.ers. pt/pages/73?news_id=620>. Acesso em: 20 mar. 2014.

FORTIN, M. Fundamentos e etapas do processo de investigação. Loures: Lusodidacta, 2006.

HENNING, R. Terapia Ocupacional nos Cuidados Paliativos aos pacientes oncológicos. Joinville, 2010. Disponível em: <http://tocoletiva.com.br/wp-content/uploads/2013/06/ TERAPIA-OCUPACIONAL-NOS-CUIDADOS-PALIATIVOS-AOS-PACIENTES-ONCOL\%C3\%93GICOS. pdf . Acesso em: 30 mar. 2014.

MARQUES, A. et al. O desenvolvimento dos cuidados paliativos em Portugal. Patient Care, Lisboa, v. 14, n. 152, p. 32-38, 2009.

OLIVEIRA, R. Cuidado Paliativo. São Paulo: Conselho Regional de Medicina do Estado de São Paulo, 2008.

OTHERO, M. Terapia Ocupacional: práticas em oncologia. São Paulo: Roca, 2010.

QUEIROZ, M. E. Atenção em cuidados paliativos. Cadernos de Terapia Ocupacional da UFSCar, São Carlos, v. 2, n. 20, p. 203-205, 2012. http://dx.doi.org/10.4322/ cto.2012.021.

WORLD HEALTH ORGANIZATION - WHO. Genebra, 2013. Disponível em: <http://search.who. int $/$ search?q=palliative + care $\&$ ie $=$ utf $8 \&$ site $=$ who $\&$ clie $\mathrm{nt}=\_$en_r\&proxystylesheet=_en_r\&output $=\mathrm{xml} \_$no $\mathrm{dtd} \& o e=U T F-8 \&$ getfield $s=$ doctype $\& u l a n g=p t-B R \& i p=$ 85.243.84.205\&access=p\&sort=date:D:L:d1 \&entqr=3\& entqrm $=0 \& u d=1 \&$ start $=20>$. Acesso em: 20 mar. 2014.

\section{Contribuição dos Autores}

Hugo Miguel Candeias Baltazar foi responsável pela concepção e redacção do presente estudo. Susana Cristina Costa Pestana orientou o estudo. Maria Raquel Rodrigues Santana co-orientou o estudo. Todos autores aprovaram a versão final do texto. 